\title{
Formaçáo inicial de professores: um campo de sentido e de compreensão das relaçóes com o magistério
}

Kelly Cristina Ducatti-Silva*

\section{Resumo}

Neste trabalho, buscamos compreender de que modo três estudantes em formação inicial de professores entram em atividade ao assumir a docência. Tal compreensão se apoia nos elementos trazidos das narrativas produzidas pelas estagiárias num contexto de experiência didática (Projeto Integrado - 2007), durante o $3^{\circ}$ ano do curso de Pedagogia. As narrativas foram instrumentos de coletas de dados, cumprindo o papel de sugerirem informaçóes de como as estudantes se posicionavam diante do seu futuro campo de atuação, a partir da relação que conseguem estabelecer com o magistério, mesmo estando em formação inicial. Isso foi possível devido à inserção dessas estudantes no ambiente escolar, uma vez que assumiram algumas conduçôes de aulas associadas às articulaçôes que fizeram ao considerarem as dimensôes envolvidas no processo de aprendizagem sobre constituir-se professor. Nesse sentido, o cenário escolar caracterizou-se como um espaço promissor para a reflexão das estudantes acerca do exercício docente. Assim, contamos com a Teoria da Atividade para compreender as diferentes relaçóes com o magistério, que foram se configurando a partir do contato que as estudantes estabeleciam com os conteúdos inerentes à docência: a sala de aula, a professora do estágio, os alunos da sala, o ensino, a aprendizagem e a própria profissão.

Palavras-chave: formação inicial de professores, estágio, relaçôes, Teoria da Atividade.

Initial teacher formation: a field of meaning and understanding of relations with the teaching profession

\section{Abstract}

This study sets out to try to understand how three students in initial teacher formation start work after taking up their teaching careers. Such an understanding is based on evidence found in narratives produced by these student-teachers in the context of teaching experience

* Doutoranda em Educação pela Universidade Estadual Paulista de Campinas (Unicamp) e docente na Universidade Estadual de Ponta Grossa. E-mail: kellyducatti@hotmail.com 
(Integrated Project - 2007), during the 3rd year of their undergraduate Pedagogy Course. These narratives were used as tools for data collection fulfilling the role of suggesting information on how the students see themselves vis-à-vis their future work, based on the relationship they manage to establish with the teaching profession, even while still undergoing their basic formation. This was done through introducing these students to the school environment, allocating them some classes based on the reflections they had made when considering what is involved in the process of learning to be a teacher. In this sense, the school setting was seen as an appropriate forum for the students' reflection on being teachers. Activity Theory was used to understand the different relationships with the teaching profession, which were formed from the contact the students had established with elements inherent to teaching: the classroom, the placement supervisor, students in the classroom, teaching, learning, and the profession itself.

Keywords: initial teacher formation, placement, relationships, Activity Theory.

\section{Introdução}

exercício do estágio é, para muitos, o primeiro contato com a profissão docente. Segundo Garcia (1999), ele define-se, em geral, como os primeiros anos de trabalho, quando o estudante se familiariza com o sistema escolar. É um período em que o aluno se esforça por aceitar as crianças, os professores, futuros colegas e supervisores, e tenta alcançar algum nível de segurança no modo como lidar com os problemas e questóes do dia a dia. Barolli (2008) também enfatiza o quanto tem sido promissor criar condiçôes didáticas para que os estudantes em formação inicial de professores possam assumir situaçóes do cotidiano da prática docente.

Parece que é no encontro inicial com a escola e, mais particularmente, com a sala de aula que os estudantes em formação vão se dando conta do que pode representar para eles próprios a escolha pela carreira do magistério. Parece que ocupar o lugar de professor, mesmo que no contexto de uma experiência ainda efêmera, já traz elementos para que o estudante comece a considerar de forma mais consequente suas escolhas.

Para compreender os elementos apresentados pelos estudantes em formação inicial, nosso objeto de estudo teve como foco as suas narrativas escritas e orais elaboradas num contexto didático a partir da realização do Projeto Integrado, sustentado pela união de três disciplinas - Fundamentos do Ensino de Ciências, Fundamentos do Ensino de Matemática e Prática de Ensino/Estágio Supervisionado -, cursadas pelos estudantes do $3^{\circ}$ ano do Curso de Pedagogia da Faculdade de Educação da Unicamp. 
No $1^{\circ}$ semestre de 2007, os estudantes tiveram um conjunto de atividades para dar início à elaboraçáo de um projeto de ensino. Houve, nesse período, visitas ao espaço escolar, exercício das narrativas e condução de algumas aulas nos primeiros anos do ensino fundamental que viabilizaram as açóes no magistério, especialmente aquelas da sala de aula. No $2^{\circ}$ semestre do mesmo ano, os docentes propuseram que os estudantes replanejassem o trabalho anterior, potencializando as novas conduçóes de aulas.

No espaço narrativo criado pelos docentes, os estudantes conseguiram repensar, levantar questóes e, principalmente, interrogar-se sobre o momento vivido com o estágio. Isso nos sugeriu a possibilidade de problematizar essas narrativas, criando uma circunstância que não se configurou propriamente como uma entrevista, mas que, sobretudo, assemelhou-se a uma conversa, que lhes possibilitou refletir sobre os elementos da própria narrativa, crenças, sensações, dúvidas ou certezas em relação a assumir a futura profissão.

A escolha do material produzido pelos estudantes ocorreu na observação da participação em sala de aula, bem como na leitura de suas narrativas. As conversas foram realizadas no final do ano de 2007. Estudamos as narrativas de formação de dez estudantes diretamente envolvidos com o contexto didático. Levantamos algumas questóes para nortear essa conversa, particularmente em relação a algumas afirmaçóes que se mostravam um pouco vagas, categóricas, ambíguas. Trouxemos para análise três casos e, para preservar a identidade dessas participantes, criamos nomes fictícios: Elis, Dalila e Maria.

No que se refere à análise, a Teoria da Atividade, num determinado momento de organização e tentativa de leitura compreensiva dos dados, funcionou como um filtro dos muitos elementos trazidos durante as leituras das narrativas e discussóes travadas dentro do grupo de pesquisa, constituindo-se, assim, num novo modo de olhar para a aprendizagem do futuro professor.

\section{Contexto teórico-prático da pesquisa}

Compreendemos que as estudantes, ao terem contato com o estágio, com todas as pessoas e objetos de estudos que dele fazem parte, entraram, de algum modo, e de diferentes formas, em atividade. Que tipo de atividade seria esta? É óbvio que, além de participarem de uma atividade de prática 
de estágio, as estudantes necessariamente faziam "coisas", trabalhavam com as crianças, produziam materiais para que os alunos realizassem outras atividades além daquelas demandadas pela professora da sala. Mas não é a essa atividade que Charlot (2000) faz referência. O autor afirma que, baseado nos estudos de Leont'ev (1978), sobre a Teoria da Atividade, todos nós, ao ingressarmos em um cenário de realizaçóes, também entramos em atividade psíquica. Há dois exemplos dados por Charlot (2000, p. 55) para que entendamos melhor o que representa esse entrar em atividade. O primeiro é de uma criança que encontra sentido em realizar determinada tarefa, e o segundo é relativo ao cenário de um crime. Imaginemos: a criança mobiliza-se, em uma atividade, quando investe nela, quando faz uso de si mesma como de um recurso, quando é posta em movimento por móbeis que remetem a um desejo, um sentido, um valor. Sabendo disso, para entrar em atividade, é preciso mobilizar-se - que é pôr-se em movimento, é investir, engajar-se em uma ocupação originada por móbiles responsáveis pela produção do movimento, ou seja, é, por exemplo, ter boas razóes para fazer algo, movimentarse por alguma coisa.

Em nosso estudo, percebemos que as estudantes entraram em atividade, inicialmente, mobilizadas pela imagem de se constituir como professoras e, nesse processo, diferentes foram os posicionamentos em relação à ideia de tornarem-se professoras.

A atividade em Leont'ev (1978) é a relação entre sua meta e seu móbil, entre o que incita a agir e o que orienta a ação. Vejamos o segundo exemplo - o crime: um crime é um conjunto de açóes que levam à morte de alguém que incomoda. O móbil do crime é o amor, o ódio, o desejo de ser rico ou poderoso. Que sentido terá matar alguém? Sua morte (resultado do crime), o fato de livrar-se de quem incomoda (meta) permite satisfazer o desejo que era o móbil do crime (Charlot, 2000, p. 55-56).

Com o auxílio dos estudos de Charlot, percebemos que nem a meta, nem o móbil, sozinhos, permitem entender o sentido do ato. Foi observado que não foram só as estudantes que estavam dispostas a correr riscos no estágio para, enfim, tornarem-se professoras que entravam em atividade, mas também aquelas que recusavam ou rompiam com a ideia de ser professora, isso porque produziram um sentido para romper com tal ideia. Vimos que, de forma particular, todas manifestavam sua singularidade, trazendo à tona elementos que despertavam o sentido de ser ou 
não professora no contexto vivido - no processo de imaginar constituirse como professora.

Nos casos anteriormente mencionados, constatamos, dentro de um mesmo contexto de formação, ou seja, das mesmas condiçóes de sustentação com o Projeto Integrado, diferentes relatos de experiências vivenciadas pelas estudantes do curso de Pedagogia.

Com a análise daqueles três casos queremos responder às seguintes questóes: Nos encontros com o cenário da escola e com as possíveis dimensóes que ela envolve, o que sustenta no estudante a ideia de tornar-se professor? Quais são os elementos que podem interferir na decisão do estagiário, fazendo com que ele confirme ou negue a noção de ser professor? Como o estudante se aproxima dessa ideia de tornar-se professor?

Ao iniciar o processo de análise para compreensão dos dados coletados, buscamos, inicialmente, na teoria da relação com o saber, de Bernard Charlot (2000), subsídios para fundamentar as experiências vividas pelas estudantes, pois, durante o estágio, as estudantes estabeleceram relaçóes diversas e diferentes, com as crianças, com o ensino, com a aprendizagem, com os professores do ensino fundamental e com as escolas. Enfim, as circunstâncias, no que diz respeito ao cenário e atores, são bastante próximas daquelas encontradas no exercício da profissão de professor. No estágio, as estudantes puderam vivenciar a rotina de um professor, elaborar o próprio planejamento de ensino e desenvolver as aulas com apoio das disciplinas articuladas pelo Projeto Integrado.

Com os encaminhamentos dados, apreendemos com os estudos de Charlot (2000) que não há construção do saber sem que haja uma relação com ele. Nesse sentido, as estudantes participantes da pesquisa criaram e cultivaram alguma relação com o saber pedagógico ao entrarem em contato com as variáveis produzidas no contexto didático do Projeto Integrado, sobretudo, com o estágio. Antes, precisamos entender a que saber/saberes estamos nos referindo e o que é a relação com ele(s). Para trabalhar essa noção, Charlot (2000) destacou que, no mundo, existem muitas "coisas" para serem aprendidas. Para ele,

[a]prender pode ser adquirir um saber, no sentido estrito da palavra, isto é, um conceito intelectual (meter coisas na cabeça), como os jovens dizem: significa, então, aprender a gramática, a matemática, a data da batalha de Marignan, a circulação do sangue, a história da arte... Mas, aprender pode ser também dominar um objeto ou uma atividade (atar os cordóes dos sapatos, 
nada, ler...), ou entrar em formas relacionais (cumprimentar uma senhora, seduzir, mentir...). (Charlot, 2000, p. 59)

No caso das estudantes em formação inicial, no âmbito da dimensão epistêmica, o saber a ser constituído se configura não somente na aquisição de conceitos, mas também no domínio de atividades vinculadas ao ensino e às relaçóes estabelecidas com todos os atores envolvidos no cotidiano da prática educativa. Parece-nos que, na conquista desse saber ou saberes, alguns estudantes recusaram a ideia de ser professor, ou se afastaram dela. Outros, nessa mesma busca pelos saberes, confirmaram a situação de ser professor e aderiram a essa imagem, influenciada por diversos atores ou objetos com os quais tiveram contato no período de estágio. Nesse percurso, as estudantes que se aproximaram do magistério, por meio do estágio, pareceram se projetar como professores e demonstraram seguir com isso após a formação.

Talvez possamos entender melhor como isso ocorre com a explanação de Charlot (2000), uma vez que, para ele, todos nós temos uma atividade intelectual, porém mobilizar ou não esse potencial depende do valor que nós atribuímos àquilo que vivenciamos. Isso se modifica de sujeito para sujeito, considerando como fator primordial a história de cada um, ou seja, os motivos que despertam o desejo de aprender num sujeito podem náo ter nenhum efeito sobre outro que tem uma história de vida singular. É a partir desse contexto que buscamos a proposta defendida por Leont'ev (1978, p. 62-63), sobre a estrutura da atividade - ilustrada por Daniels (2003, p. 116) da seguinte forma:

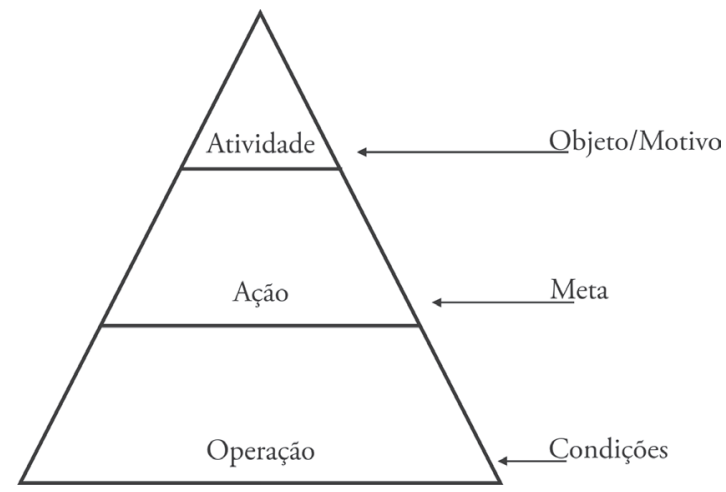

Fig. 1. A Estrutura hierárquica da atividade 
Compreendemos, a partir da figura apresentada por Daniels (2003), que, para o sujeito entrar em atividade, há um processo hierárquico. Nesse sentido, a atividade é impulsionada conforme a relação entre objeto e motivo. Daí sucede a açáo do sujeito (individual ou no grupo) carregada de intençóes que contemplam a questão: $\mathrm{O}$ que pode ser feito? A referida ação é impulsionada por uma meta consciente que indica o aspecto operacional, e isso, por sua vez, norteia o sujeito na busca de atender algo ou alguma coisa, mediado pelas condiçóes refletidas na seguinte questão: Como pode ser feito?

Retomamos a ideia de Charlot sobre o valor que nós atribuímos àquilo que vivenciamos e relacionamos com a estrutura que orienta a entrada do sujeito em uma atividade. Assim, percebemos que o principal fato que distingue uma atividade de outra é a diferença de como seus objetos relacionam-se com o motivo de determinada atividade.

Desse modo, entendemos que os elementos que constituem a atividade que o sujeito realiza nos oferecem pistas sobre como cada uma das estagiárias em formaçáo inicial de professores, ao relacionar objeto e motivo, ingressa ou não na atividade de imaginar-se como professora dos anos iniciais.

Veremos na seção seguinte que os dados sugerem diferentes relaçôes com o magistério e o modo como essas se configuram a partir do contato que as estudantes estabelecem com os conteúdos inerentes à docência: a sala de aula, a professora do estágio, os alunos da sala, o ensino, a aprendizagem e a própria profissão.

\section{Os dados à luz da Teoria da Atividade}

[...] o sentido não é algo que aparece diretamente nas respostas das pessoas, nem nas representaçóes que as alimentam, apenas aparece disperso na produçáo total da pessoa, pelo que necessitamos da interpretação e de nossas construçôes para produzir inteligibilidade sobre ele. (Gonzáles Rey, 2005, p. 32)

Em nossa pesquisa, quando estão no estágio, os estudantes do curso de Pedagogia têm, de forma geral, a necessidade de desenvolver um projeto de ensino no estágio e planejar esse trabalho durante as aulas em que são participantes. Individualmente, traçam metas e estáo encarregados de di- 
versas ações com o propósito de alcançá-las. Alguns observam o contexto da sala de aula e, nesse contato inicial, assustam-se ou não com aquilo que vivenciam. Dependendo das situaçóes vivenciadas, as estudantes trazem para o processo de reflexão, por meio das narrativas, suas limitaçóes ou potencialidades.

A prática me assustou bastante. Foi por causa de ir para o estágio. Ir para o estágio toda semana e desenvolver projeto, ir para sala de aula. Foi ai que eu me dei conta de que não era isso que eu queria. Foi a partir dai. Quando o curso vinha caminhando de forma mais teórica, estava tudo bem, a hora que chegou a parte prática que en assustei, falei: "Ops! E agora?" [...] eu estava lá na frente, tinha 30 crianças olhando para mim. Eu falei: "O que eu estou fazendo aqui?". Minha vontade era sair correndo. A hora que eu vi todo mundo perguntando, prestando a atenção no que eu estava falando, $e$ levantar a mão, perguntando o que é isso, o que é aquilo que nós vamos fazer, falei: "Não. É muita criança. É muita coisa para eu fazer. Eu não quero." (Maria, N86-94)

Maria elaborou seu projeto e ingressou no estágio para desenvolvêlo. Enquanto planejava os conteúdos a serem trabalhados na escola, a relação com a docência aparentemente caminhava sem complicaçóes, mas quando se deparou com a sala de aula, mais especificamente, com 30 crianças, iniciava-se a partir daquele momento um processo de indagaçóes sobre o fazer docente e a percepçáo da estudante ao tentar imaginar-se professora. $\mathrm{Ou}$ seja, entrar nessa atividade causava-lhe desconforto.

Outros estudantes, com os mesmos objetos relativos à docência, estabeleciam diferentes relaçôes, reagiam talvez "menos assustados" com a situação vivida em sala de aula e apresentavam as potencialidades que o contato com a escola e com os alunos pôde propiciar na relaçáo com os saberes da docência.

Depois desse tempo todo eu acho que, apesar de tudo, apesar do meu cansaço, eu acho que criança... quando eles falam com aqueles olhinhos querendo aprender, é um coisa muito gostosa. Eu acho que dá força, que a essência da criança de ser curiosa, de ser provocadora de "Ah...eu não acredito em você, me prova?". De ser contestadora. Eu acho muito bacana criancinha ser contestadora, ser birrentinha mesmo. A gente fala que criança é chata. Não sei se é chata, eu acho mesmo que é o jeito de ser da criança que é assim. É de encarar tudo como uma surpresa, 
como uma novidade e viver aquilo intensamente. Acho que isso dá força, então eu acho que o que mudou na minha relação com as crianças é isso. Acho que é a minha força. Que quando eu sinto que eu não tenho criatividade, mas eu olho para uma coisa... Por exemplo, as miniaturas que eu vi lá no meu projeto, a hora que eu olhei aquilo eu pensei logo nelas brincando de supermercado e a possibilidade de imaginar as crianças brincando e aprendendo e discutindo tudo aquilo e trabalhando com o dinheirinho, alguma coisa divertida, gostosa, que eles iam se envolver. A possibilidade de pensar nas crianças envolvidas num trabalho me fez parar e saiu o projeto e saiu todo o meu projeto. Acho que elas só me apontam assim... Esperança talvez. Então, quando eu me sentir a professora que eu não quero ser... cansada, sem criatividade, sem ânimo, acho que vai ser só olhar para as crianças que tem perto assim que acho que vai... vai trazer tudo de novo. Essa é minha esperança. (Elis, N58)

Elis, implicada com a atividade de imaginar-se como professora, encontra no olhar curioso da criança a força que precisa para dar continuidade ao seu processo de formação e realiza o planejamento das atividades imaginando a aprendizagem da criança.

No estágio com os professores dos anos iniciais do ensino fundamental, as estudantes auxiliam nas situaçóes de ensino e aprendizagem dos alunos durante o período em que permanecem na escola. Ao vivenciarem a prática docente, expóem as condiçóes de intervenção e as operações - o como poderia ser feito - a partir das circunstâncias criadas no interior da escola formalizada por sua comunidade.

Ai, será que vou conseguir, eu quero tanto que dê certo, que vá tudo bem e dai o que acontecia era que nos primeiros dias eu chegava na sala morrendo de medo de fazer besteira, sentava perto dos alunos e ficava [...] tentando chegar perto deles e eles sempre me sorriam e eu sorria de volta e cumprimentava eles, mas eu não conseguia realmente interagir com eles, por exemplo, quando eles tinham alguma dúvida eles esperavam para pedir para a professora, eles não falavam comigo, não pediam para mim, eles não me reconheciam enquanto alguém que podia estar os ajudando, e dai nas primeiras semanas, duas, três semanas eu sofri com isso porque para mim era difícil, eu queria conseguir intervir, eu queria conseguir participar, conseguir ajudar, mas eu não conseguia como, porque eu ficava não, não vou chegar e vou interromper a hora que eles tiverem na atividade. "O que você está fazendo, quer ajuda?" Falava assim: "Não, eu não vou interrompề-los." Quando eu cheguei no primeiro dia eu falei que estava à disposição para quem precisas- 
se, que pode me chamar e então eu não vou. Só que isso começou a me causar muito incômodo, eu comecei a avaliar a hipótese de perguntar para alguém: "Você está precisando de ajuda?" E nessas três primeiras semanas, pelo menos para mim, foi dificil, que eu realmente queria participar, eu realmente estava ali para participar e o que aconteceu um pouco antes dessa narrativa foi que um dia eu estava sentada e eu senti um dedinho no meu ombro, ai era $o$, eu tenho mania de achar que ele era menino... Ah! Mas ele é bem mais velho que eu, sabe? Ele falou: "Eu não estou conseguindo entender essa conta que a professora passou." Eu falei: "Ah, eu sei fazer, você quer que eu te ajude? Eu entendi o que a professora falou." E ai ele: "Ai, me ajuda, vai." Era uma conta de dividir, ele tava com bastante dificuldade na divisão e foi na mesma época que a gente estava fazendo divisáo no ábaco com a professora. Então, nossa, eu fiquei: uau! Eu posso ajudar ele competentemente, porque agora eu sei fazer isso. Dai eu conversei com ele, mostrei e fiz a conta com ele, ajudei tal e tal e ele acabou conseguindo fazer a conta e dali para frente ele começou a ter facilidade com esse tipo de conta e eu fiquei muito feliz. Depois que esse primeiro me chamou, quebrou o gelo, dai eu sento na sala já quando alguém olha para mim chama direto, então, eu conseguia interagir com eles todos os dias bastante tempo, o tempo todo e às vezes em vários momentos eu senti que eu estava conseguindo fazer a diferença, por exemplo, a dona Antônia, nossa ela tem uma garra, você coloca um texto na máo dela, você sabe que para ela é um texto difícil, ela vai ler 20, 30, 40, 70 vezes até ela entender. Ela tem uma garra impressionante e ela estava chateada com as continhas de matemática porque ela fazia, fazia, fazia e no final não sabia se estava certo ou não e ficava naquela expectativa de ver a professora resolver. Um dia eu virei para ela e falei: "Você já ouviu falar de prova real?" Ela: "O que é isso?" Ai eu a ensinei a tirar prova real da conta, então, para ela aquilo foi tudo, sabe? Ela sabia ver se estava certa na continha, a hora que ela terminava, ela conferia. Então eu estava muito feliz, muito contente porque eu achava que estava dando muito certo. (Dalila, N165)

Dalila, nesse depoimento, demonstra ter encontrado uma maneira de interagir com os alunos adultos para atuar no ensino que tanto queria desenvolver. Percebeu que, mesmo em situação de estágio, poderia fazer a diferença na vida daqueles alunos.

Por outro lado, a estudante Maria, envolvida com a situação de estágio, quer respostas imediatas sobre como tornar-se uma professora - $\mathrm{O}$ que deve ser feito para isso? Na tentativa de entrar em atividade, pensa sobre os encaminhamentos que poderiam existir para dizer: "Ser professora é..." 
Às vezes, eu paro e penso: "Poderia ter alguma coisa para dizer ser professora é assim, assim, assim. Tentar ser assim... E tentar ser assim." Mesmo quando o professor João falava para não ser assim. Eu chegava no estágio e via que não dava para ser do jeito que ele falava. Entendeu? (Maria, N99)

Maria parece entender que há um jeito certo de ser professor e, com a intenção de colocar em prática o que apreendeu, avalia que não é possível ser aquela professora sugerida pelo formador.

No caso da estagiária Elis, a compreensão é outra. Em seu depoimento, indica que é preciso cumprir as exigências vinculadas à formação de professores, caracterizadas pelo conjunto de disciplinas reunidas na experiência didática da qual participou durante o exercício do Estágio Supervisionado. Nessa perspectiva, associou o cumprimento das etapas desse momento do curso com as "altas provas" existentes em um Reality Show e assim descreveu:

É que estava passando na época, tem uma amiga na sala que é a Bruna, e ela gosta de assistir novelas, reality show e a gente sempre brincava com ela: " $E$ ai, o que está acontecendo no Big Brother?” Mas a gente nem tinha tempo para assistir, ai ela contava, mais ou menos, como era a prova da comida, altas provas que eles tinham que fazer dentro da casa para não sair, e mais ou menos o nosso grupo começou a conversar: "Nossa, a gente está num reality show", porque a gente tem altas provas para fazer, a gente fica acordado, prova de resistência, a gente passa madrugadas e madrugadas fazendo trabalhos, mas no final a gente não sabe se vai ser vencedor, se a gente vai ser realmente professor, se vai dar tudo certo. (Elis, N4)

A estagiária refere-se às diversas atividades que foram realizadas durante os dois semestres de 2007: busca de uma escola para o exercício de estágio, contato com diretores, professores e alunos, conhecimento da proposta da professora, formulaçáo de ideias sobre o que poderia contribuir com a professora da escola, pesquisa, conversas e negociaçóes com a professora, planejamento de uma atividade de ensino que envolvesse conhecimentos da Matemática e Ciências, configurando um projeto interdisciplinar, apresentaçôes e discussões nas aulas de prática de ensino, desenvolvimento do plano de aula nas escolas, condução de aulas, contando com 30 ou 40 alunos em sala, e avaliação das atividades nos encontros com os professores formadores para posterior replanejamento do 
trabalho. Desse modo, os dois semestres foram marcados por afazeres semelhantes àqueles assumidos pelos professores em exercício nos anos iniciais. De acordo com a estagiária, passaram por "altas provas", pois, com a tensão de assumir aulas, algumas estudantes ficavam sem dormir, na tentativa de ter o máximo de controle sobre o planejamento das aulas. Feito isso, comparado às provas, náo sabiam se conseguiriam ser professoras. Aqui, o ato de ser professora é compreendido como ir além das provas, vencê-las não é o suficiente.

Com o que foi percebido nos casos das estagiárias, buscamos analisar: Como se dá o envolvimento das estudantes do curso de Pedagogia com a docência ainda na formação inicial? No intento de compreender tal questão, vamos analisar o motivo por trás da atividade desenvolvida por elas.

Leont'ev (1978, p. 62-63), ao propor a estrutura que organiza os termos apresentados anteriormente neste texto, também esclarece, por meio de um exemplo, seus significados para tornar plausível a Teoria da Atividade:

Quando estão caçando, os membros de uma tribo têm, individualmente, metas separadas e estáo encarregados de diversas açóes. Alguns estão afugentando um bando de animais na direção de outros caçadores que abatem as feras, e outros membros têm outras tarefas. Essas açóes têm metas imediatas, mas o real motivo está além da caçada. Juntas, essas pessoas têm em vista obter comida e roupa - permanecer vivas. Para entender por que açôes separadas são significativas, é preciso compreender o motivo por trás da atividade como um todo. A atividade é guiada por um motivo.

\begin{tabular}{|c|l|}
\hline \multicolumn{2}{|c|}{1 - Quadro Elis } \\
\hline \multicolumn{2}{|c|}{ Atividade = Imaginar a si mesma constituindo-se como professora. } \\
\hline Necessidade & Desenvolver um projeto de ensino na escola. \\
\hline Motivo & Aprender o ofício de ensinar com criatividade. \\
\hline Móbil (inicial) & Ser professora. \\
\hline Móbil (no processo do estágio) & Ser a professora ideal, encontrada no estágio. \\
\hline Resultado & Projeta-se como professora alfabetizadora. \\
\hline
\end{tabular}




\begin{tabular}{|c|l|}
\hline \multicolumn{2}{|c|}{ 2 - Quadro Dalila } \\
\hline Atividade $=$ & \multicolumn{1}{|c|}{ Imaginar a si mesma constituindo-se como professora. } \\
\hline Necessidade & Desenvolver um projeto de ensino na escola. \\
\hline Meta & Ser uma professora competente. \\
\hline Móbil (inicial) & Ser professora. \\
\hline $\begin{array}{c}\text { Móbil (no processo } \\
\text { do estágio) }\end{array}$ & $\begin{array}{l}\text { Ser a professora capaz de mudar a vida das pessoas para } \\
\text { melhor, a ideia de professora que Freire expôs em suas } \\
\text { obras. }\end{array}$ \\
\hline Resultado & Projeta-se como professora de jovens e adultos. \\
\hline
\end{tabular}

\begin{tabular}{|c|l|}
\hline \multicolumn{2}{|c|}{ 3 - Quadro Maria } \\
\hline Atividade $=$ & \multicolumn{1}{|c|}{ Imaginar a si mesma constituindo-se como professora. } \\
\hline Necessidade & Desenvolver um projeto de ensino na escola. \\
\hline Meta & Cumprir com as exigências das disciplinas. \\
\hline Móbil (inicial) & $\begin{array}{l}\text { Ser professora sem a prática, apenas com aportes } \\
\text { teóricos. }\end{array}$ \\
\hline Móbil (no processo do & $\begin{array}{l}\text { Ter controle da sala de aula ao executar um planejamento, } \\
\text { contando que ele vai permitir o controle absoluto. }\end{array}$ \\
\hline Resultado & $\begin{array}{l}\text { Rompe com a ideia de projetar-se como professora, mas } \\
\text { náo abandona o curso. }\end{array}$ \\
\hline
\end{tabular}

Vimos que as estudantes em pauta entraram em atividade a partir do ato de se imaginarem constituindo-se como professoras. As necessidades também são iguais nos três casos, modificando: os processos de mobilização, meta e, consequentemente, o resultado.

Parece simples definir desse modo, mas compreender o que acontece com as estudantes em formação, num contexto delineado como o nosso caso, não é tão fácil assim. É necessário estudarmos alguns conceitos que nos fornecerão mais elementos, propiciando algum tipo de entendimento para o que estamos apresentando.

Para Charlot (2000, p. 54), a relação com o saber acontece como um processo que se desenvolve no tempo, e isso implica atividades. Para desen- 
volvê-las, o sujeito deve mobilizar-se. Para haver essa mobilização, a situação deve apresentar um significado ao sujeito. Assim, nas análises presentes nos estudos realizados pelo autor sobre a relação com o saber, frequentemente, são utilizados estes três conceitos: mobilização, atividade e sentido. Queremos, aqui, aproveitá-los em nossos casos, pois os três conceitos nos auxiliam na leitura das informações coletadas durante a pesquisa, bem como no cotejamento dos significados em relação ao processo de construção de saberes das estudantes de Pedagogia, ao se aproximarem ou se afastarem do magistério.

Nessa perspectiva, intentamos elucidar cada um desses conceitos da seguinte forma: a) Mobilizaçáo - tal conceito implica na ideia de movimento. É uma dinâmica interna. Um pequeno exemplo disso ocorre quando observamos na fala de um estudante: "Eu quero ser professor porque eu não me imagino fazendo outra coisa. Nasci para ser professor." Essa parece ser uma expressão intrínseca ao sujeito. Mesmo com as interferências externas, ele permanece com a ideia de tornar-se professor. Sabemos que há vários fatores negativos, inclusive, que poderiam colaborar para a recusa dessa profissão, e mesmo assim o estudante se movimenta, assume para si a ideia de ser um professor. Em outra direção, está o conceito de motivação, que evidencia o fato de que se é motivado por alguém ou por algo (de fora), portanto, é algo extrínseco ao sujeito. Um exemplo disso seria escolher ser professor por haver no mercado de trabalho oportunidades de emprego ou porque algum membro da família teve forte influência sobre a escolha feita. b) Atividade - possui uma dinâmica interna, entretanto, essa dinâmica supóe uma troca com o mundo e com os outros, momento em que o sujeito encontra metas desejáveis, meios de ação e outros recursos para se manifestar e investir na experiência que pensa realizar (Charlot, 2000, p. 55). Entendemos que entrar em atividade por meio da imagem que se tem e do cenário concreto da escola é uma forma de o estudante aproximar-se da ideia de tornar-se professor. c) Sentido - é sempre o sentido de um enunciado, que diz algo do mundo para alguém. Tem significação porque foi produzido pelas relaçóes entre os signos que o constituem. Assim, podemos inferir que, nos encontros com o cenário da escola e com as possíveis dimensóes que ela envolve, o estudante encontra algo que lhe produz sentido, que sustenta a ideia de tornar-se professor. Tem sentido aquilo que produz inteligibilidade, que aclara algo no (e sobre o) mundo. Em nosso caso, sobre ser professora. Os elementos que interferem na adesão do estagiário, fazendo com que ele confirme ou negue a possibilidade de ser professor, 
estão no sentido de uma atividade, na relação entre sua meta e seu móbil, entre o que incita a agir e o que orienta a ação, levando a um determinado resultado (Charlot, 2000, p. 55-6).

\section{Consideraçóes finais}

As estudantes foram estimuladas, por meio de um conjunto de atividades inseridas nas disciplinas, a estabelecerem relaçóes diversas com o mundo e com atores da escola em que realizaram o estágio. Essas circunstâncias, no que diz respeito ao cenário escolar, são bastante próximas daquelas encontradas no exercício da profissáo docente, já que, no estágio, as estudantes puderam vivenciar a rotina de um professor, elaborar o próprio planejamento de ensino e desenvolver as aulas apoiadas num contexto interdisciplinar.

Com a teoria da atividade, analisamos as trajetórias em determinado momento de estágio das estudantes, ao aderirem ou não à atividade de imaginarem a si mesmas constituindo-se como professoras. Vimos que o ato em questão carrega marcas de continuidade e ruptura do vínculo com a docência durante a formação, na medida em que as estagiárias, a seu modo, constroem relaçóes com o conjunto de elementos que caracterizam a docência: atuaçáo na sala de aula, o contato com o aluno, o contato com a professora da escola, a implicação com o ensino, a preocupação com a aprendizagem dos alunos, os desafios que percebem na profissão.

Nesse sentido, com os elementos já mencionados e destacados nas narrativas das estudantes, podemos interpretar que, enquanto Maria traz como móbil ser professora apenas com aporte teórico, ao inserir-se no campo de estágio, esse móbil não se sustenta, pois há a necessidade de relacionar-se com a prática pedagógica da escola. Parece-nos que, com a descontinuidade do móbil, tem-se como resultado o rompimento da ideia de ser professora. Os dados indicam que, na relação da estudante com os objetos que impulsionam o processo da atividade, não há a reconstrução de outro móbil que sustente o Motivo, para se projetar como professora. Parece-nos, ainda, que a insuficiência de móbil interferiu na decisão de Maria sobre a possibilidade de tornar-se professora.

Nos casos das estudantes Elis e Dalila, parece existirem a continuidade e o avanço sobre tal ideia. 
Temos visto, desse modo, que não há construção do saber sem uma relação com ele (Charlot, 2000). No caso das estudantes, em formação inicial, o saber a ser apropriado por elas configura-se não somente na aquisição de conceitos disciplinares, mas também no domínio de saberes vinculados ao ensino, à profissão do professor, constituídos nas relaçôes estabelecidas com todos os envolvidos no cotidiano da prática educativa. Parece-nos que, na apropriação desses saberes, alguns estudantes podem se afastar da ideia de ser professor, já outros podem se aproximar dela.

\section{Referências}

BAROLLI, E. Narrativas e espaços intersticiais: uma analogia. In: III CIPA Congresso Internacional sobre pesquisa (auto) biográfica. Comunicação oral, Natal, Universidade Federal do Rio Grande do Norte, set. 2008.

CHARLOT, B. Da relação com o saber: elementos para uma teoria. Porto Alegre: Artmed, 2000.

DANIELS, H. Vygotsky e a pedagogia. São Paulo: Edições Loyola, 2003.

GARCIA, C. M. Formação de Professores: para uma mudança educativa. Portugal: Porto Editora, 1999.

GONZÁLEZ REY, F. Pesquisa qualitativa e subjetividade: os processos de construção da informação. (Trad. Marcel Aristides Ferrada Silva). São Paulo: Pioneira Thomson Liarning, 2005.

LEONT'EV. A. O desenvolvimento do psiquismo. Lisboa: Livros Horizonte, 1978.

Recebido em: 25 maio 2010

Aceito em: 15 jun. 2010 